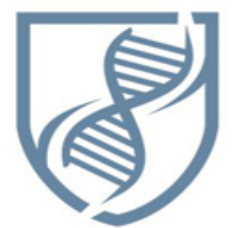

Journal of Bioscience and Applied Research
JBAAR

WWW JBAAR ORG

\title{
Developmental defects of cerebral cortex in maternally diabetic and aluminum intoxicated rat pups and their amelioration by Morus alba
}

\author{
Gamal Badawy ${ }^{1 凶}$, Hassan El-Sayyed ${ }^{2}$, Sobhy Hassab Elnabi ${ }^{1}$, Ibrahim El-Elaimy ${ }^{1}$, \\ Eman Al Shehari ${ }^{1}$ \\ ${ }^{1}$ Department of Zoology, Faculty of Science, Menoufiya University, Shebeen El-koom, Egypt. \\ ${ }^{2}$ Department of Zoology, Faculty of Science, Mansoura University, Mansoura, Egypt. \\ ${ }^{\square}$ Corresponding author, Email: Gamalbadawy940@yahoo.com
}

\begin{abstract}
The present study aimed to investigate the possible ameliorative effect of crude water extract of Morus alba leaves on developmental defects of cerebral cortex of rat pups maternally subjected to diabetes and/or aluminum (Al) intoxication. One hundred and forty fertile male and virgin female albino rats were used for the experimentation. The pregnant rats were arranged into seven groups. The study included five integrated approaches and all proved that treatment with Morus alba leaves extract led to a marked amelioration for the developmental defects caused by either diabetes or $\mathrm{Al}$ intoxication at all levels of the study. At the ultrastructural level, the cerebral cortex of the latter exhibited massive cytological alterations of Purkinje cells (PC) and Karyolysis of chromatin material. The cytoplasm appeared translucent and enclosed by either fragmented or vesiculated RER. Mitochondria appeared electron-dense with ill-differentiated cristae. Cytoplasmic vacuoles were detected. However, pups of mothers received Morus alba extract and subjected to $\mathrm{Al}$ intoxication and/or diabetes showed partial amelioration of cytological structure of PC. The nuclear envelope was regularly arranged and enclosed by normal euchromatin. The cytoplasmic organelles were rearranged and approximately restored their pattern. It can therefore be concluded that leaves extract of Morus alba has marked ameliorative effects against developmental defects of cerebral cortex in pups of diabetic and $\mathrm{Al}$ intoxicated pregnant albino rats.
\end{abstract}

Keywords: Aluminum, Comet assay, Diabetes, Development, Morus alba, TEM.

\section{Introduction}

Diabetes mellitus (DM) represents the major public health disease and Aluminum ( $\mathrm{Al})$ is a well known neurotoxic affecting both human and animal beings. Peripheral nerve involvement is highly frequent in DM and it has been documented that one third of diabetic patients have peripheral neuropathy (Comi and Corbo, 1998; Fazan et al., 2010). Phytotherapy is frequently used throughout the world for a range of diabetic presentations and considered to be less toxic and free from side effects than synthetic drugs (Mutalib, 2015). Therefore, investigations of such medicines have become particularly important. Although the brain represents about $2 \%$ of the body weight in mammals; it receives $15 \%$ of cardiac output and accounts for $20 \%$ of total body oxygen consumption. This energy requirement is largely driven by neuronal demand for energy to maintain the generation of action potentials. Although this intense energy requirement is continuous; even brief periods of oxygen or glucose deprivation result in neuronal death (Van Dijk et al., 2015). Mitochondria are increasingly recognized as subcellular organelles that are essential for generating the energy that fuels normal cellular function while, at the same time, they monitor cellular health in order to make a possible rapid decision to initiate a programmed cell death. These organelles are essential for neuronal function because the limited glycolytic capacity of these cells make them highly dependent on aerobic oxidative phosphorylation for their energetic needs. However, oxidative phosphorylation is a major source of endogenous toxic free radicals (Wallace, 1999). The fact that mitochondria are the major generators and direct targets of reactive oxygen species led several investigators to foster the idea that oxidative stress and damage in mitochondria are contributory factors to several disorders including diabetes. Since brain possesses high energetic requirements, any decline in brain mitochondria electron chain could have a severe impact on brain function of neurodegenerative diseases (Moreira et al., 2007). Diabetes is associated with impaired glucose utilization, 
deficits in mitochondria activity and metabolic dysfunction (Brownlee, 2005). Brain damage is now a well-established complication of diabetes, but its pathophysiological basis remains controversial (Ryan, 2006). Until recently, most research on this topic was devoted to demonstrate that hypoglycemic events are the primary cause of neurocognitive dysfunction. This was a plausible hypothesis because the central nervous system (CNS) has very limited stores of glucose and other substrates, but neurons have a very high rate of glucose utilization; any reduction in glucose availability would probably induce neuroglycopenia, ultimately leading to significant neuronal damage. Support for this view came from research demonstrating that profound hypoglycemia could produce neuronal necrosis (Auer et al., 1984) and induce distinctive patterns of neuropathological (Auer et al., 1989) and neurocognitive impairment in humans who had experienced very low blood glucose levels over an extended period of time (Chalmers et al., 1991). Tomlinson and Gardiner (2008) reported that neurons have a constantly high glucose demand. Neuronal glucose uptake depends on the extracellular concentration of glucose, and cellular damage can ensue after persistent episodes of hyperglycemia which causes up to fourfold increase in neuronal glucose levels. If this persists, then intracellular glucose metabolism leads to neuronal damage; this phenomenon is often referred to as glucose neurotoxicity. The latter is a serious consequence of long-term diabetes, and the clinical syndrome is referred to as diabetic neuropathy which is a serious and disabling complication that contributes to increased morbidity and mortality in diabetic patients (Thomas and Eliasson, 1984). Loss of nerve fibers, axonal atrophy, degeneration and remyelination, as well as vascular abnormalities is major structural changes in peripheral nerves of human diabetic neuropathy (Johnson et al., 1986). However, reduction of myelinated fiber size in the distal peripheral nerve has been established as a reproducible structural change in experimentally diabetic rats (Sharma and Thomas, 1987). The widespread use of products made from or containing $\mathrm{Al}$ is ensuring its presence in our body. Certain uses lead to the presence of $\mathrm{Al}$ in drinking water and foodstuffs (Krewski et al., 2007). The main sources of $\mathrm{Al}$ in human diet include tea, beer, baked products, drinking water, toothpaste, Al-based antacids, Al cookware and some canned beverages (Rao et al., 1999). Progression of diabetic neuropathy is related to glycaemic control in both type 1 and type 2 diabetes (Vinik et al., 2000). The duration of diabetes and degree of metabolic control are the two major predictors of the development of neuropathy and determinant of its severity (Harati, 2007). Little is known about the epidemiology of the autonomic neuropathy in different types of diabetes (Comi and Corbo, 1998) and much remains to be learned about the natural course of diabetic autonomic neuropathy (Vinik et al., 2000). Several hypotheses have been proposed to explain pathogenesis of diabetic polyneuropathy, but the real cause is not well understood. For most, there is strong experimental support but the details of each mechanism and their possible interrelationships remain, so far, unanswered (Harati,
2007). Several studies have indicated that hyperglycemia can be controlled via different sorts of medicinal plants (ElSayyad et al., 2015). Experimental diabetic mice treated with Fructus Ligustri Lucidi (Hao et al., 1992), extract of Ephedrae herba and 1-ephedrine (Xiu et al., 2001), and diabetic rats treated with extract of Matteccia orientalis (Basnet et al.,1993), ethanolic extracts of Luffa aegyptiaca (seeds) and Carissa edulis (leaves) (El-Fiky et al.,1996), the Chinese herbal mixture [ quei Fu DHW ] (Cheng et al., 2001), hot water Folium Mori extracts (Iizuka et al., 2001), Momordica charantia, Eugenia jambolana, Mucuna pruriens and Tinospora cordifolia (Grover et al., 2001) Smallantus sonchifolius (Aybar et al., 2001), aqueous extract of Rubus fructicosis L. and Globularia alypum L. leaves (Jouad et al., 2002), mulberry (Andallu and Varadacharyulu, 2002). El-Hilaly et al. (2006) demonstrated potent hypoglycemic activity and relatively non-toxic nature of a lyophilized aqueous extract of Ajuga iva L. (AI) whole plant in normal and streptozotocin (STZ) -diabetic rats. AI-extract $(10 \mathrm{mg} / \mathrm{kg}$; oral $)$ reduced plasma glucose levels after acute (single) and sub-chronic dosing both in normal and diabetic rats. In STZ -diabetic rats, a single dose as well as repeated treatment with the AIextract produced a significant decrease in plasma cholesterol and triglyceride levels. Reports indicate that mulberry leaves contain proteins, carbohydrates, calcium, iron, ascorbic acid, b-carotene, vitamin B-1, folic acid and vitamin D (Bose, 1989). The aim of the present study was to investigate the possible ameliorative effect of crude water extract of Morus alba leaves on developmental defects of cerebral cortex of rat pups maternally subjected to diabetes and/or $\mathrm{Al}$ intoxication.

\section{Materials and Methods}

\section{Animals and grouping}

1- Principles of animal care and use were carefully followed during the conducting of the present study. One hundred and forty fertile male and virgin female albino rats (Rattus norvegicus) weighing $180 \pm 20 \mathrm{~g}$ were purchased from Hellwan Breeding Farm, Ministry of Health, Cairo, Egypt and used for the experimentation. Rats were housed in individual cages and maintained in a room with good ventilation at $23{ }^{\circ} \mathrm{C}$. They were fed on standard diet free from excess fats and free access of food and water was allowed ad libitum throughout the experimental period. Females were mated in a special cage (1male/2 females) overnight and gestation was determined in the next morning by the presence of sperm in unstained native vaginal smear. The pregnant rats were arranged into seven groups (15 individuals each); control, experimental diabetic, diabetic and Morus alba, Al-intoxicated, Al intoxicated and Morus alba, diabetic and Al intoxicated, diabetic and $\mathrm{Al}$ intoxicated group plus Morus alba. At the end of the experimental period i.e. after $7 \& 14$ days from parturition, pups of both control and experimental groups were anesthetized by an intraperitoneal injection of sodium pentobarbital solution $(50 \mathrm{mg} / \mathrm{kg}$ body weight), sacrificed, dissected and cerebral cortex was separated and processed differently according to the required investigations. 


\section{Water extraction of Morus alba leaves}

Mulberry leaves were washed and dried in a hot air oven at $50{ }^{\circ} \mathrm{C}$ for $6-8 \mathrm{~h}$. The dried material was ground to a fine powder and kept in an airtight container at $4{ }^{\circ} \mathrm{C}$ until further use. Four grams dried Morus alba leaves were extracted with $50 \mathrm{x}(\mathrm{w} / \mathrm{v})$ of hot water $\left(85^{\circ} \mathrm{C}\right)$ for $3 \mathrm{~h}$. The extract was filtered with Whatman No.1 filter paper and concentrated to a volume of $1 / 20$ of the initial solution volume by heating at a no boiling temperature near $100{ }^{\circ} \mathrm{C}$, and then dried completely under vacuum at $25^{\circ} \mathrm{C}$. The dried extract $(\mathrm{w} / \mathrm{w}=0.5 \mathrm{~g}$, yield $=15 \%)$ was used during experimentation. The applied dose of Morus alba extract was $100 \mathrm{mg} / \mathrm{kg}$ body weight (El-Sayyad et al., 2011) and was orally administered after the induction of diabetes every other day till the end of experimentation.

\section{Induction of diabetes}

DM was induced experimentally in all pregnant rat groups except the control and $\mathrm{Al}$ intoxicated group by a single intraperitoneal injection of STZ $(60 \mathrm{mg} / \mathrm{kg})$ in citrate buffer $(0.05 \mathrm{M}, \mathrm{pH} 4.5)$ at the $5^{\text {th }}$ day of gestation for two consecutive days and injected within $10 \mathrm{~min}$ of dissolution (Povoski et al., 1993). Control animals were treated with physiological saline as a vehicle. Maternal hyperglycemia was verified by measuring the blood glucose level. A level of more than $300 \mathrm{mg} / \mathrm{dl}$ was selected for this study.

\section{Induction of Aluminum-toxicity}

Aluminum chloride (AlCl3) of highest purity was purchased from El-Nasr Pharmaceutical Chemicals, Menoufiya, Egypt. It was dissolved in physiological saline solution and intragastrically administered by stomach intubation every other day from the 6th day of gestation till the end of the experiments. The applied dose was $80 \mathrm{mg} / \mathrm{kg}$ body weight (Cranmer et al., 1986).

\section{Body weight}

The weights $(\mathrm{g})$ of both control and experimental pups were recorded.

\section{Determination of Al content}

Al content of cerebral cortex of 14 days old control and experimental pup groups and their mothers at the end of experiment was determined by using Perkin Elmer Model 5000 spectrophotometer (Van Ginkel et al., 1990).

\section{Light microscopic investigation}

Specimens of cerebral cortex from both $7 \& 14$ days old control and experimental pup groups were fixed in $10 \%$ phosphate-buffered formalin for 24 hours, dehydrated in ascending grades of ethyl alcohol, cleared in xylene and mounted in molten Paraplast at $58-62^{\circ} \mathrm{C}$ and processed to generate $5 \mu \mathrm{m}$ thick paraffin sections. The obtained sections were stained with hematoxylin and eosin (HE) and subjected to microscopic examination.

\section{Transmission electron microscopic investigation}

Specimens of cerebral cortex from both control and experimental pups aged 7 and 14 days were separated and immediately fixed in $2.5 \%$ glutaraldhyde and $2 \%$ paraformaldhyde in $0.1 \mathrm{M}$ cacodylate buffer $(\mathrm{pH}$ 7.4). After rinsing in $0.1 \mathrm{M}$ cacodylate buffer, they were post fixed in a buffered solution of $1 \%$ osmium tetraoxide at $4^{\circ} \mathrm{C}$ for 1.5 hour and dehydrated in ascending grades of ethyl alcohol and embedded in epoxy-resin. Ultrathin sections were cut with a diamond knife on an LKB microtome and mounted on grids, stained with uranyl acetate and lead citrate and examined with a Joel transmission electron microscope (TEM).

\section{Single cell gel electrophoresis (comet assay)}

For comet assay, specimens of cerebral cortex of control and experimental 14 days old pups were homogenized in chilled homogenizer buffer, $\mathrm{pH} 7.5$, containing $75 \mathrm{mmol} / \mathrm{L}$ $\mathrm{NaCl}$ and $24 \mathrm{mmol} / \mathrm{L}$ Na2EDTA to obtain a $10 \%$ tissue solution. A Potter-type homogenizer was used and cerebral cortex samples were kept on ice during and after homogenization. Six microlitres of cerebral cortex homogenate was suspended on $0.5 \%$ low melting agarose and sandwiched between a layer of $0.6 \%$ normal melting agarose and a top layer of $0.5 \%$ low melting agarose on fully frosted slides. The slides were kept on ice during the polymerization of each gel layer. After the solidification of the $0.6 \%$ agarose layer, the slides were immersed in a lysis solution (1\% sodium sarcosinate, $2.5 \mathrm{~mol} / \mathrm{L} \mathrm{NaCl}, 100$ $\mathrm{mmol} / \mathrm{L}$ Na2EDTA, $10 \mathrm{mmol} / \mathrm{L}$ Tris- $\mathrm{HCl}, 1 \%$ TritonX-100 and $10 \%$ dimethylsulfoxide) at $4^{\circ} \mathrm{C}$. After $1 \mathrm{~h}$, the slides were placed in electrophoresis buffer $(0.3 \mathrm{~mol} / \mathrm{L} \mathrm{NaOH}, 1$ $\mathrm{mmol} / \mathrm{L} \mathrm{Na}$ EDTA, $\mathrm{pH} 13$ ) for $10 \mathrm{~min}$ at $4{ }^{\circ} \mathrm{C}$ to allow DNA to unwind. Electrophoresis was performed for $10 \mathrm{~min}$ at $300 \mathrm{~mA}$ and $1 \mathrm{~V} / \mathrm{cm}$. The slides were neutralized with Tris-buffer, $\mathrm{pH} 7.5$, and stained with $20 \mathrm{~g} / \mathrm{mL}$ ethidiumbromide for $10 \mathrm{~min}$. Each slide was analyzed using the Leitz Orthoplan epifluorescence microscope (Wetzlar, Germany). One hundred cells were analyzed on each slide using the comet assay II automatic digital analysis system. Perspective tail length $(\mathrm{m})$ is the distance of DNA migration from the center of the body of the nuclear core and is used to evaluate the DNA damage. The tail moment is defined as the product of the tail length and the fraction of the total DNA in the tail (Tail moment=tail length $\mathrm{x} \%$ of DNA in the tail). Both tail length and tail intensity were measured automatically by image analysis software (Sasaki et al., 1997). 


\section{Determination of DNA fragmentation}

Extraction of DNA was done according to the method of Aljanabi and Martinez (1997) and Hassab El-Nabi (2004). Briefly, freshly specimens of cerebral cortex from both $7 \&$ 14 days old pups weighing $10 \mathrm{mg}$ were squeezed in Eppendorf tubes, lysed with 600 microlitre ( 1) buffer (50 $\mathrm{mM} \mathrm{NaCl}, 1 \mathrm{mM} \mathrm{Na}_{2}$ EDTA, $0.5 \%$ sodium dodecyle sulphate, $\mathrm{pH}$ 8.3) and shaked gently. The mixture was incubated overnight at $37^{\circ} \mathrm{C}$. For protein precipitation, an amount of 2001 of saturated $\mathrm{NaCl}$ was added to each sample, shaked gently and centrifuged at $12000 \mathrm{rpm}$ for 10 minutes. The supernatant was transferred to new Eppendorf tubes and the DNA was precipitated by 6001 cold isopropanol. The mixture was inverted several times till fine fibers of nucleic acids appeared, at which time the mixture was centrifuged for 5 minutes at $12000 \mathrm{rpm}$. The supernatant was then removed and the pellets (DNA \& RNA) were washed with $500170 \%$ ethanol and centrifuged at $12000 \mathrm{rpm}$ for 5 minutes. The supernatant was decanted and the tubes were plotted on Whatman filter paper to dry for 10 minutes. The pellets were resuspended in $50 \quad 1$ of Tris EDTA buffer (10 mM Tris, 1 mM EDTA, pH8). The resuspended DNA was incubated for 30-60 minutes with a loading mix (Rnase + loading buffer) and then added into the agarose gel wells. A gel was prepared with $2 \%$ electrophoretic grade agarose containing $0.1 \%$ ethidium bromide $(200 \mathrm{~g} / \mathrm{ml})$. The DNA samples were mixed with loading buffer $(0.25 \%$ bromophenol blue, $0.25 \%$ xylene cyanole FF and $30 \%$ glycerol) and loaded into the wells (2 $\mathrm{g}$ of DNA/Lane) with a standard molecular-sized ladder marker (Pharmacia Biotech., USA). The gel was electrophoresed at a current of $\mathrm{mA}$ for 2.5 hours using the submarines gel electrophoresis machine. The DNA was visualized and photographed with illumination under ultraviolet (UV) light using a photodocumentation hood (Fisher Scientific, Pittsburgh, PA, USA) equipped with a Polaroid 667 film with an orange filter (Kodak, Rochester, NY, USA). The UV reacts with the ethidium bromide to show the DNA fragments. Apoptotic bands appeared and located at $200 \mathrm{bp}$ and its multiples.

\section{Statistical analysis}

All data sets were expressed as mean \pm SEM. The data were analyzed statistically for normal distribution (Student's $t$ test) to find out the significant difference (Gupta, 1995) and homogeneity of variance using SPSS software for windows, version 11 . Values where $p<0.05$ were considered statistically significant.

\section{Results}

Figure 1 illustrates body weight of all pup groups control or maternally subjected to diabetes and/or intoxicated with Al. As the figure shows, maternally diabetic 7 and 14 days old pups had overgrowth weight (macrosomia) compared with marked depletion of body weight in pups maternally intoxicated with Al. Treatment with Morus alba extract led to a marked amelioration of body weight but was still above the normal levels in diabetic group comparing with pups maternally intoxicated with Al.

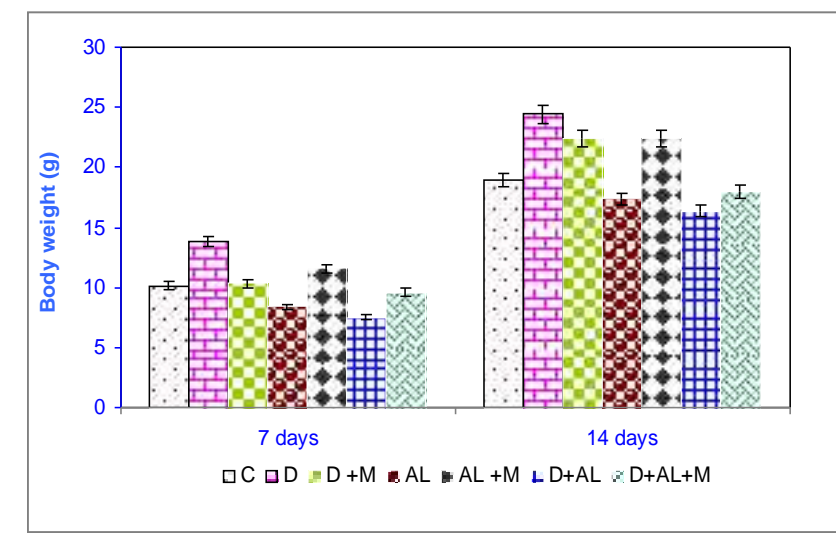

Fig. (1) Body weight (g) of 7 and 14 days old pups of both control and experimental groups.

Figure 2 shows that aluminum content of mothers and their14 days old pups reached its highest level in either $\mathrm{Al}$ intoxicated alone or in combination with diabetic. Treatment with Morus alba leaves extract resolute the Al content burden in cerebral tissues but was still above the normal level in $\mathrm{Al}$ and/or diabetes.

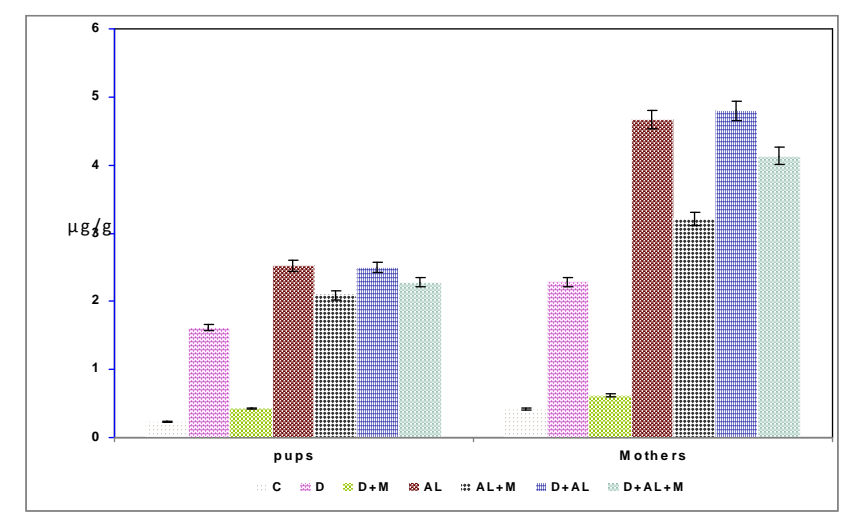

Fig. (2) Al content of cerebral cortex of 14 days old control and experimental pup groups and their mothers at the end of experiment.

\section{Light microscopic observations}

Light microscopic observations of cerebral cortex of 7 days old pups of control revealed that the cerebral cortex is formed of four main cell layers; external Granular layer (GL), Molecular layer (ML), Purkinje cells (PC) layer and internal granular layer. The outermost external granular layer appeared thick when compared with that of the internal granular layer and localized at the periphery of the Molecular layer. It was formed of closely packed oval or rounded-shaped neurons. The Molecular layer occupied the innermost region and composed of a narrow strip of darkly stained neuronal cells comparing with the external granular layer. The Purkinje Cells aligned in single cell layer at the periphery of the internal granular layer. Each was composed of large round-shape cell with centrally located vesicular nuclei with prominent nucleoli (Fig. 3A). The 
cerebral cortex of pups of diabetic mother showed disrupted architecture structure comparing with the control. The external and internal granular layer appeared disorganized with neuronal cell spaces manifested massive neuronal cell degeneration. The Purkinje cells layer lacked differentiation and not clearly identified. The internal granular cells appeared fragile and loosely arranged with marked neuronal cell loss (Fig. 3B). Pups of diabetic mothers treated with Morus alba extract exhibited amelioration of the histological structure with peculiar arrangement of different cell layers (Fig. 3C). Pups maternally intoxicated with $\mathrm{Al}$ showed degeneration of both Purkinje and granular cells (Fig. 3D). Partial amelioration of Purkinje cells was detected in pups of $\mathrm{Al}$ intoxicated mothers and received Morus alba extract (Fig. 3E). Pups maternally diabetic plus $\mathrm{Al}$ intoxication showed fibrillar structure of molecular layer and degeneration of the granular and Purkinje cells (Fig. 3F). However pups of mothers received Morus alba and subjected to diabetes and intoxicated with $\mathrm{Al}$ restored the almost pattern structure of Molecular layer and granular layer but lacked differentiation of Purkinje cells (Fig. 3G).

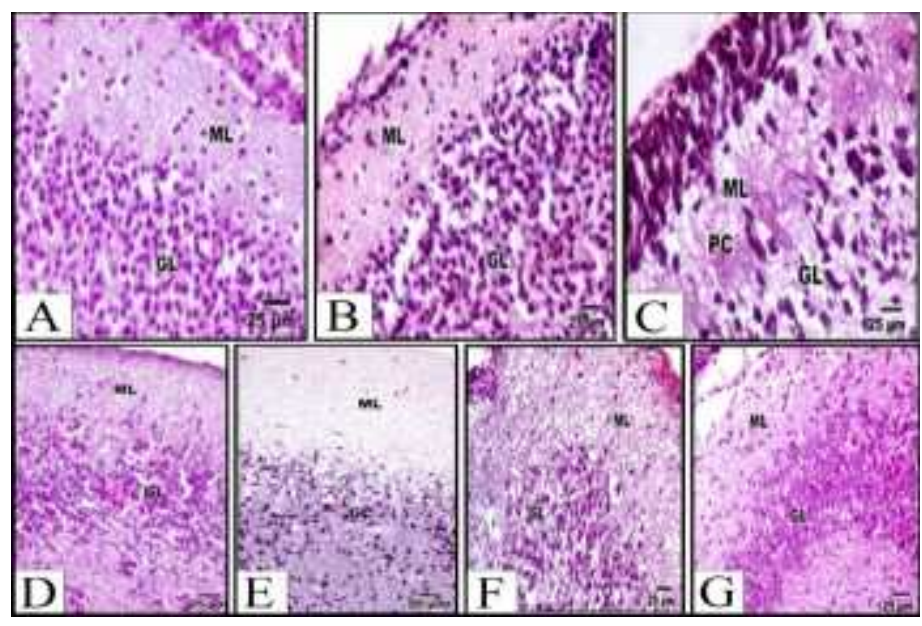

Fig. (3) (A-G): Photomicrographs of transverse histological sections of cerebral cortex of 7 days old pups of both control and experimental groups. A: control. B: Maternally diabetic, C: Maternally diabetic and received Morus alba extract, D: Maternally intoxicated with $\mathrm{Al}$, E: Maternally intoxicated with $\mathrm{Al}$ and received Morus alba extract, F: Maternally diabetic plus Al intoxication, G: Maternally diabetic plus Al intoxication and received Morus alba extract.

In 14 days old control pups, the cerebral cortex attained more differentiation of the external and internal granular layer. The internal granular layer attained much more thickening. It is formed of closely packed rounded-shaped neuronal cells. The neurons were infiltrated with intercellular spaces called islands or glomeruli. The neurons exhibited large darkly stained nuclei and thin peripheral cytoplasmic coat. The Purkinje cells became arranged in a single row at the peripheral margin of the internal GL. The nucleoli were clearly evident (Fig. 4A). Maternally diabetic pups showed less convoluted folia and massive degeneration of both purkinje cells and granular cells, the internal GL was comparatively reduced and showed less dense grouping neuronal cells separated by widened spaces. There was a marked increase of pyknotic cell death of PC and appeared with clumped nuclear chromatin. The internal GCs possessed massive reduction of their neuronal cells and glomerular spaces were markedly widened (Fig. 4B). Maternally diabetic pups who received Morus alba extract showed numerous branched folia and regenerated Purkinje and granular cells beside amelioration and cerebral cortex cell layers arrangement. (Fig. 4C). Pups maternally intoxicated with $\mathrm{Al}$ showed massive loss of Purkinje cells (Fig. 4D). Pups maternally intoxicated with $\mathrm{Al}$ and received Morus alba extract showed regeneration of Purkinje cells (Fig. 4E). Pups maternally diabetic plus Al intoxication showed massive degeneration of both Purkinje cells and granular layers (Fig. 4F). Pups maternally diabetic plus Al intoxication and received Morus alba extract showed partial regeneration of both Purkinje and granular cells (Fig. 4G).

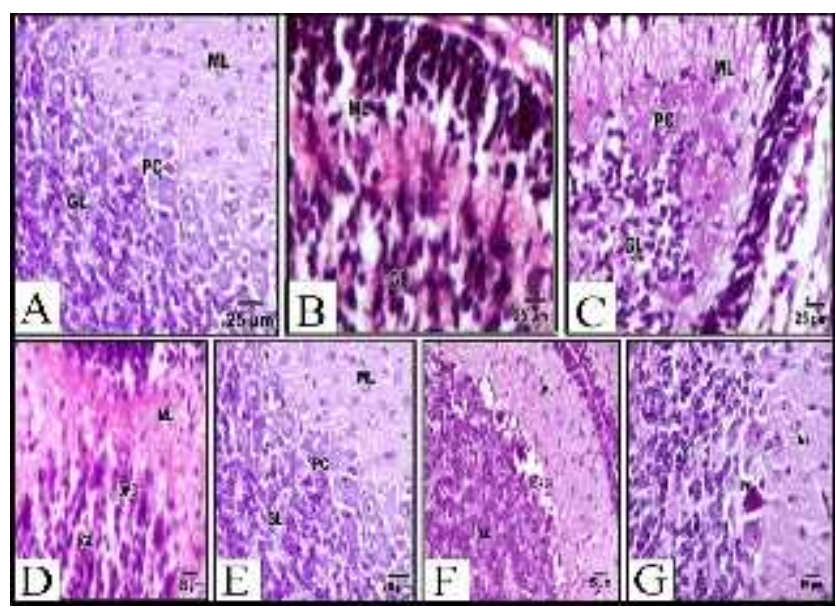

Fig. (4) (A-G): Photomicrographs of transverse histological sections of cerebral cortex of 14 days old pups of both control and experimental groups. A: control. B: Maternally diabetic, C: Maternally diabetic and received Morus alba extract, D: Maternally intoxicated with $\mathrm{Al}, \mathrm{E}$ : Maternally intoxicated with $\mathrm{Al}$ and received Morus alba, F: Maternally diabetic plus $\mathrm{Al}$ intoxication, G: Maternally diabetic plus $\mathrm{Al}$ intoxication and received Morus alba extract.

\section{TEM observations}

In control 7-day old pups, the Purkinje cells took the form of conical shaped structure. The nucleus almost occupied the cell body. The nucleus showed fine electron dense heterochromatin at the periphery of nuclear envelope. The cytoplasm was enclosed by abundant mitochondria, rough endoplasmic reticulum (RER) and polysomes. These cytoplasmic organelles encircled the nucleus in characteristic manner (Fig. 5 C1 \& C2). Maternally diabetic pups showed Purkinje cells with convoluted nuclear envelope and cytoplasm having vesiculated RER and atrophied mitochondria (Fig. 5 D1 \& D2). Pups maternally diabetic and treated with Morus alba showed partial amelioration of Purkinje cells and their cytological structures (Fig. 5 DM1 \& DM2). 


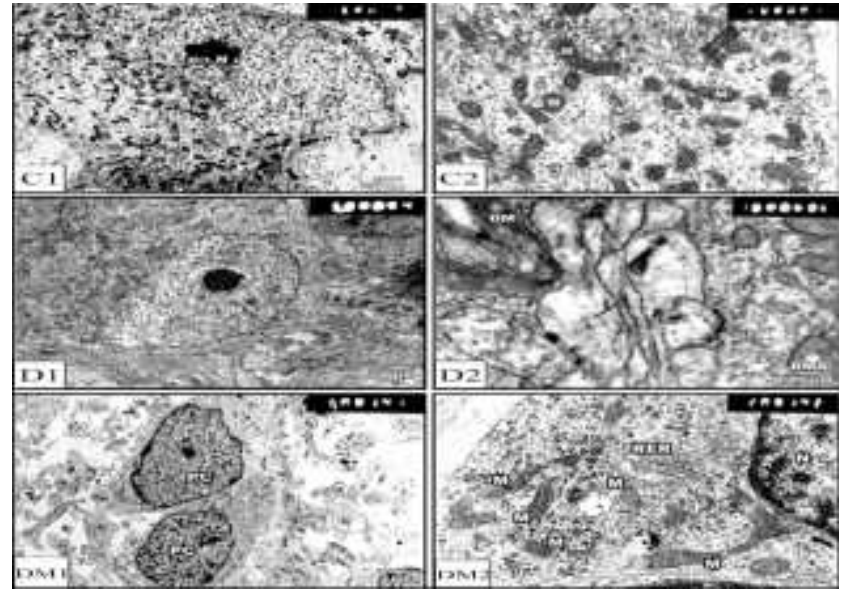

Fig. (5) (C1-DM2): TEM of cerebral cortex of 7days old pups. C1 \& C2: Control, D1 \& D2: Maternally diabetic, DM1 \& DM2: Maternally diabetic and treated with Morus alba extract.

Maternally Al intoxicated pups showed karyolysis of chromatin material of Purkinje cells and deterioration of cytoplasmic organelles including degenerated mitochondria and vesiculation of rough endoplasmic reticulum (Fig. 6 AL1 \&AL2). Pups maternally intoxicated with aluminum and received Morus alba extract showed partial amelioration of nuclear chromatin and cytoplasmic organelles including mitochondria and RER (Fig. 6 ALM1ALM2). Maternally diabetic and Al intoxicated pups showed pyknotic purkinje cells and Purkinje cell with karyolysed nuclei having cytoplasm with abundant atrophied mitochondria and fragmented RER (Fig. 6 DAL1 \& DAL2). Pups maternally diabetic, Al intoxicated and received Morus alba extract showed partial amelioration of Purkinje cell and cytoplasmic organelles (Fig. 6 DALM1 \& DALM2).

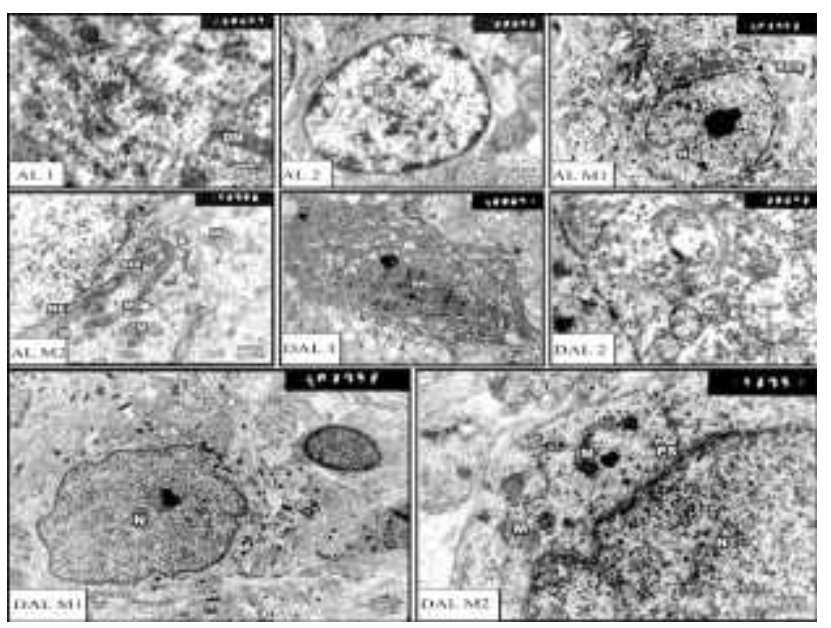

Fig. (6) (AL1-DALM2): TEM of cerebral cortex of 7 days old pups. AL1 \& AL2: Maternally intoxicated with Al, ALM1-ALM2: Maternally intoxicated with aluminum and received Morus alba extract, DAL1 \& DAL2: Maternally diabetic and intoxicated with Al, DALM1 \& DALM2:
Maternally diabetic plus intoxication with aluminum and received Morus alba extract.

Control 14 days old pups showed normal cytoplasmic organelles including mitochondria, RER, polysomes and centrally located nuclei (Fig. 7 C1 \& C2). Maternally diabetic pups showed abnormal convolution of nuclear envelope, karyolysis of chromatin material of Purkinje cells, atrophied mitochondria and vesiculated RER (Fig. 7 D1 \& D2). Pups maternally diabetic and treated with Morus alba showed amelioration of Purkinje cells and their cytoplasm (Fig. 7 DM1 \& DM2).

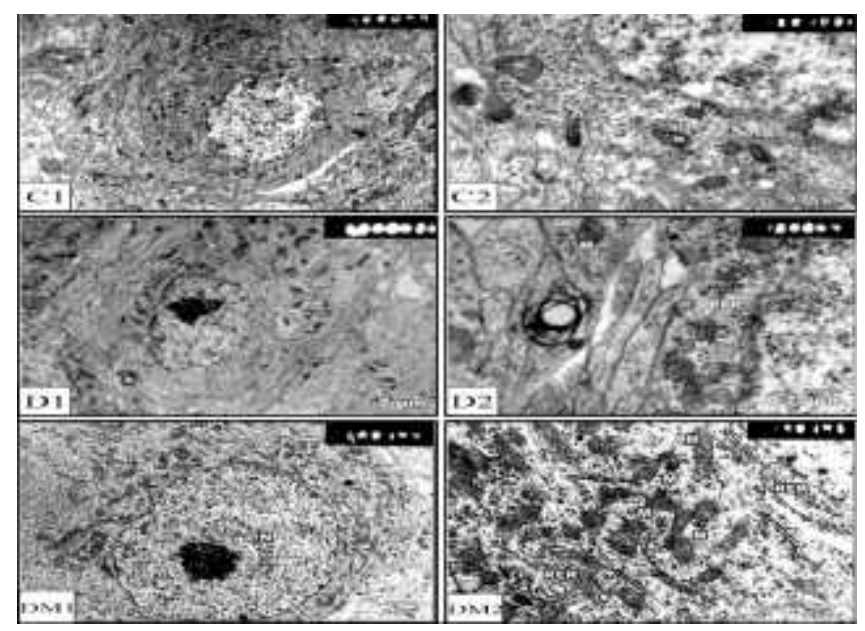

Fig. (7) (C1-DM2): TEM of cerebral cortex of 14 days old pups. C1 \& C2: Control, D1 \& D2: Maternally diabetic, DM1 \& DM2: Maternally diabetic and treated with Morus alba extract.

Pups maternally intoxicated with Al showed karyolysis of chromatin material of Purkinje cell nuclei (Fig.8 AL1 \& AL2). Pups maternally intoxicated with aluminum and received Morus alba extract showed amelioration of cytological alterations (Fig.8 ALM1-ALM2). Pups maternally diabetic and intoxicated with Al showed abnormal cytological alterations of Purkinje cells (Fig.8 DAL1 \& DAL2). Pups maternally diabetic plus intoxicated with aluminum and received Morus alba extract showed somewhat normal cytoplasmic organelles (Fig.8 DALM1 \& DALM2). 


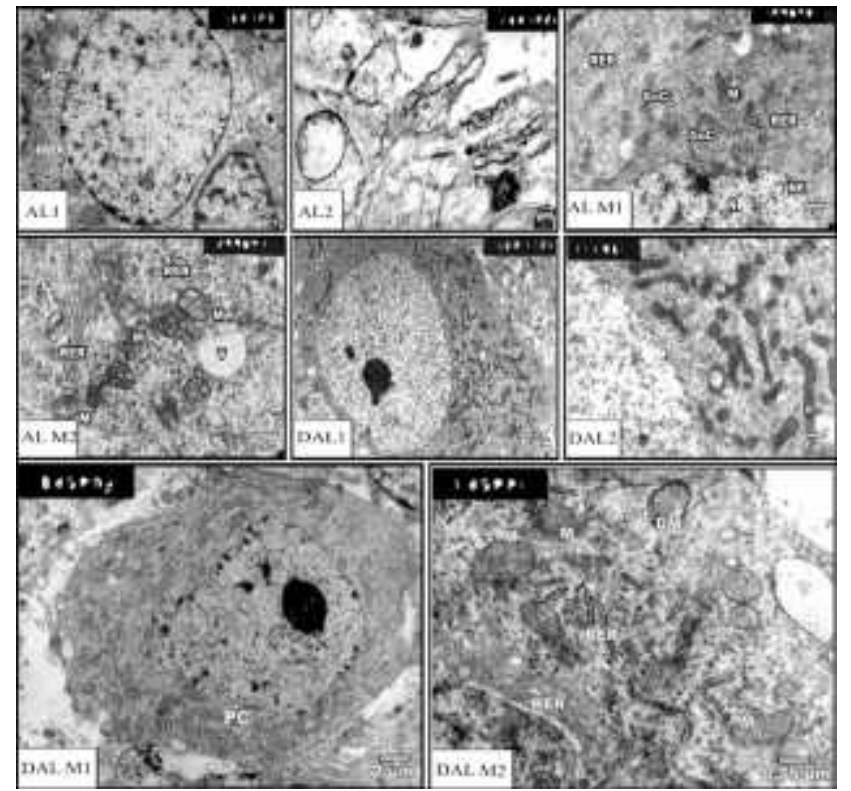

Fig. (8) (AL1-DALM2): TEM of cerebral cortex of 14 days old pups. AL1 \& AL2: Maternally intoxicated with Al, ALM1ALM2: Maternally intoxicated with aluminum and received Morus alba extract. DAl1 \& DAl2: Maternally diabetic and intoxicated with Al, DALM1 \& DALM2: Maternally diabetic plus intoxication with aluminum and received Morus alba extract.

\section{Comet assay}

Cerebral neuronal cells of 14 days old pups of both diabetic and/or $\mathrm{Al}$ intoxicated mothers exhibited increased stretching apoptotic cells (Fig. 9) and tail length (Fig. 10). Pups of treated mother besides Al intoxication and/or diabetes revealed reduction of neuronal cells with DNA damage.

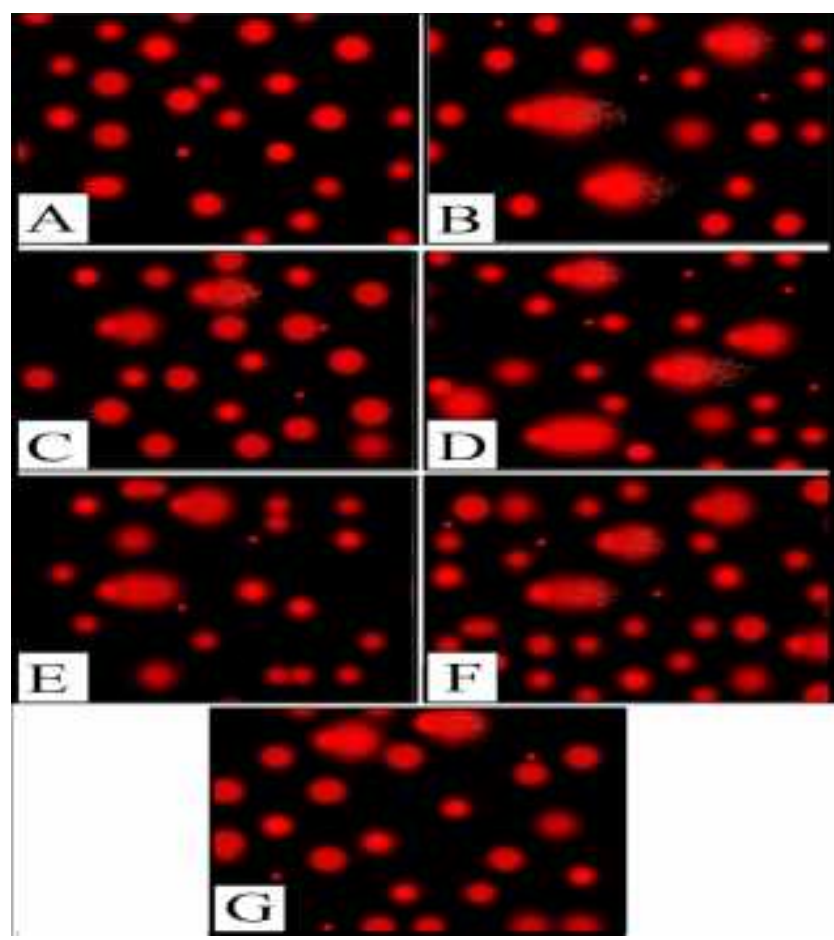

Fig. (9) Photomicrographs of cerebral cortex cells of control and experimental 14 days old pups analyzed by comet assay. The "dark/red" round spot represents the intact DNA without migration. The less dark "comet shaped" area adjacent to the nucleus represents DNA breaks that are small enough to move in the gel. A: Control, B: Maternally diabetic showing detached cerebral cells. C: Maternally diabetic and received Morus alba extract showing less damaged DNA, D: Maternally intoxicated with $\mathrm{Al}$ showing numerous detached cells. E: Maternally intoxicated with $\mathrm{Al}$ and received Morus alba extract showing decreased DNA damage. F: Maternally diabetic plus Al intoxication showing increased DNA damage. G: Maternally diabetic plus $\mathrm{Al}$ intoxication and received Morus alba extract showing reduction of DNA damage.

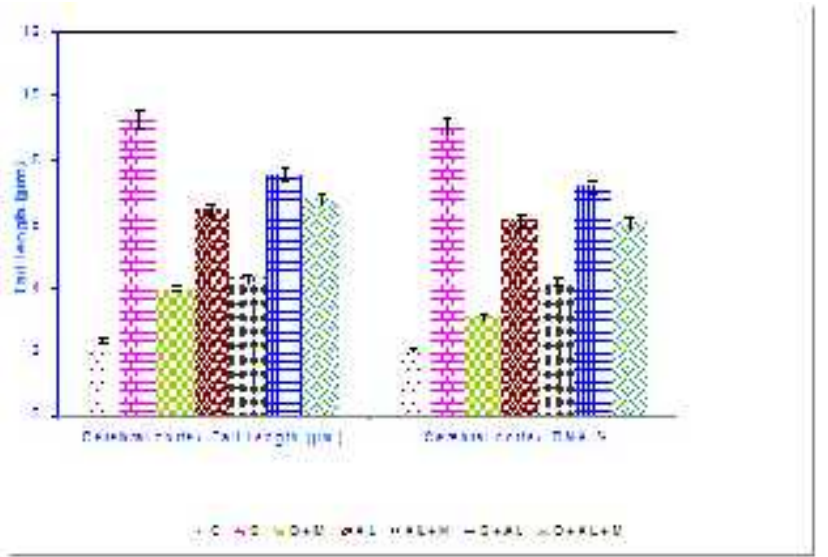

Fig. (10) Tail Length $(\mu \mathrm{m})$ and DNA concentration of cerebral cortex of control and experimental 14 days old pups.

\section{DNA fragmentation}

Cerebral neuronal cells of pups at $7 \& 14$ days old of both diabetic and/or Al intoxicated mothers possessed genomic DNA fragmentation. Highest incidence of genomic DNA fragmentation was markedly increased in pups of $\mathrm{Al}$ intoxicated mother alone or in combination with diabetes. On the other hand, pups of mother received Morus alba besides either $\mathrm{Al}$ intoxication and/or diabetes revealed resolution of DNA damage especially in diabetic or Alintoxicated groups (Fig. 11).

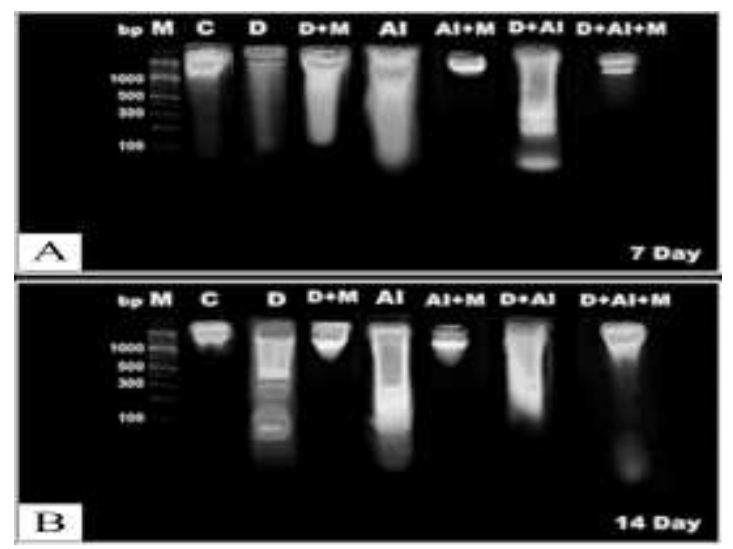

Fig. (11) DNA fragmentation of cerebral cortex of control and experimental 7 days (A) and 14 days (B) old pups. 


\section{Discussion}

The present findings showed that maternally diabetic 7 and 14 days old pups had overgrowth weight (macrosomia) comparing with decreased body weight of pups maternally intoxicated with Al. The overgrowth of body size was sustained during suckling period may be a result of depending of pups on breast-feeding of diabetic mother who may influenced by increased glucose level. Similar findings were detected in offspring of experimental diabetic animals (Holemans et al., 1999). This pattern of experimental diabetes is closely similar to the human diabetic disease and has adverse effects on fetal development and metabolism leading to increase incidence of macrosomia in offsprings of diabetic mother. The observed macrosomia attributed by Buchanan and Kitzmiller (1994) to the increased metabolic demands of pregnancy which require hormonal regulation of carbohydrate, protein, and lipid metabolism. Reduced insulin activity in pregnant diabetic women leads to a metabolically abnormal environment. As a result, diabetic embryopathy (birth defects and spontaneous abortions) occurs in the sixth to seventh weeks of gestation, and diabetic fetopathy (predominantly macrosomia and fetal hyperinsulinemia) occurs in the second and third trimesters. Freinkel (1980), attributed macrosomia to the increased placental transport of glucose and other nutrients due to an increased availability at the maternal site, resulting in fetal and neonatal macrosomia. Normally, the developing embryo uses both aerobic and anaerobic metabolic pathways. However, when embryonic and fetal circulation is established, the embryo is exposed normally to higher concentrations of oxygen (Ornoy et al., 1996). During that time, the embryo must develop its antioxidant defense mechanism, slowly increasing the activity of the major antioxidant enzymes. Ornoy (2007) reported a significant decrease in the activity of endogenous antioxidant enzymes in embryos and yolk sacs of diabetic mothers aiding with altered metabolism in overgrowth of pups. However, the evident reduction of body weight of pups observed in the present study supported the findings of Muller et al. (1992) and Sharma \& Mishra (2006). Decreased body weight may result from inhibition of fetal growth and differentiation of body organs as a result of $\mathrm{Al}$ intoxication

as well as decrease food intake plus organs intoxication in dams. Al is a neurotoxicant and it is known that accumulation of $\mathrm{Al}$ leads to a large number of neurological disorders (Yokel, 2000). There is retention of a fraction of Al that enters the brain, suggesting its potential for accumulation with repeated exposures. Weberg et al., (1986) demonstrated that the consumption of high dose Al containing antacids during pregnancy increased substantially the plasma $\mathrm{Al}$ concentration of the mother. It has been also reported that exposure of rabbits to excess $\mathrm{Al}$ during gestation and lactation led to the impairment of neuromotor maturation like that of the present study and deficits in neurobehavioral performance in their offspring (Yokel, 1985). Al is a highly neurotoxic element and has been suggested to play a role in degeneration of nerve cells in the brain of human and experimental animals (Yumoto et al., 2001; Kumar and Gill, 2014). It has been also reported that $\mathrm{Al}$ was involved in the etiology of several human pathologies like dialysis dementia, amyotropic lateral sclerosis (Linton et al., 1987), senile dementia of Alzheimer type (AD) and development of the brain in fetus and sucklings (Muller et al., 1992). Human prematurely born infants who received intravenous feeding solutions containing $2.5 \mathrm{ppm}$ or more of $\mathrm{Al}$ showed remarkable retardation of neurological development compared to those receiving feeding solution containing $0.22 \mathrm{ppm}$ (Bishop et al., 1997). It has been reported that considerable amounts of $\mathrm{Al}$ administered to pregnant and/or lactating rats was crossed the blood brain barrier and deposited into the brain of fetuses and suckling young via the transplacental passage and/or maternal milk which remained persistent throughout their lifetime (Yumoto et al., 2001). The intracellular distribution of $\mathrm{Al}$ among organelles varies but lysosomes, mitochondria and nuclei were reported to be the major sites of binding (Dobson et al., 1998). Salts of Al may bind to DNA and RNA (Matsumoto et al., 2004).

Exposure of neuronal cells to high glucose was found to increase mtDNA damage and compromised the DNA repair machinery (Madsen-Bouterse, et al., 2010). Singab et al. (2005) studied the hypoglycemic activity of the flavonoids rich fraction of $70 \%$ alcohol extract of Egyptian Morus alba root bark in STZ-induced diabetic rats. The authors found that administration of Egyptian Morus alba root bark for 10 days significantly reduced the amount of the glucose from the control level to a lower level and significantly increased the insulin level from control to a high level. Eddouks et al. (2005) reported that a single oral administration of the aqueous extract $(20 \mathrm{mg} / \mathrm{kg})$ of Triticum repens caused a significant decrease in blood glucose levels in STZ- diabetic rats. The results obtained from maternally diabetic pups can be attributed to the hypoglycemic activity of Morus alba leaves extract. Morus alba has been reported to have antioxidant and antidiabetic activities (Mazumder et al., 2012 and Shams-Ardekani et al., 2013). Mizisin et al., (1997) examined nerve biopsy samples from two cats with spontaneously occurring diabetes and reported that the predominant nerve fiber abnormalities observed were restricted to the myelin sheath and Schwann cell. Reactive, degenerative and proliferative Schwann cell changes were evident but the most striking abnormality encountered was splitting and ballooning of the myelin sheath. These observations highlighted the significance of Schwann cell injury in the pathogenesis of diabetic neuropathy. The latter is a heterogeneous disorder(Vinik et al., 2000; Harati, 2007) with high morbidity. It encompasses a wide range of abnormalities affecting proximal and distal peripheral sensory as well as motor nerves and the autonomic nervous system (Vinik et al., 2000). Distal symmetric sensory or sensorimotor polyneuropathy was the most common type of diabetic neuropathy (Comi and Corbo, 1998). In the predominantly large-fiber type symmetric polyneuropathies, loss of ankle reflexes, decreased position and vibratory senses and sensory ataxia were present (Harati, 2007). Large-fiber 
neuropathies may involve sensory or motor nerves. Human diabetic polyneuropathy was described recently as the most common chronic complication of diabetes that remains the least understood (Andriambeloson et al., 2006). Despite the diversity of the reported clinical features, it seems that its morphological hallmark is the degeneration of the peripheral nerves. In fact, several reports on human nerve biopsies of diabetic patients demonstrate an axonal loss, greatest in distal nerves, in a multifocal way (Dyck and Giannini, 1996). Several groups of investigators have described segmental demyelination and axonal degeneration in nerves of rats with chronic experimental diabetes (Yagihashi et al., 1979) but most of them used alloxan to induce diabetes. Several authors who investigated STZ-diabetes described segmental demyelination and remyelination as well as abnormalities of the paranodal myelin at a similar rate as for the control animals (Sharma et al., 1981), suggesting these alterations to be more related to aging (Jeronimo et al., 2008). Thomas et al. (1990) described a reduction in the myelin thickness mainly in the small myelinated fibers of the tibial nerves in chronic STZ-diabetic rats especially if the induction of diabetes was at early stages of life. At later stages, the axon size was consistently reduced in diabetic animals compared to controls. Fazan et al. (2010) showed that chronic STZdiabetes was able to cause demyelination. In the acute animals, no signs of demyelination were present in any of the nerves with STZ-diabetes. In the first case, glycation of the myelin proteins would account for myelin destruction and consequent demyelination. On the other hand, Harati (2007) reported that glycation of collagen and laminin could lead to a reduction in nerve growth factor, leading to axonal atrophy. It is possible that interactions between several direct and indirect metabolic consequences of insulin deficiency, hyperglycemia, as well as genetic and environmental factors are required for the emergence of diabetic neuropathies.

Light microscopic studies of renal nerves in STZ-model of chronic diabetes revealed a decrease in the number of small myelinated fibers in diabetic animals (Sato et al., 2004). It seems that the formation of advanced glycation end products may be a unifying bridge between the two major hypotheses since it explains many of the diabetic complications (Harati, 2007). In terms of peripheral neuropathy, the protein glycation cascade suggested by Harati (2007) may lead either to demyelination or axonal atrophy demonstrated in the present study. A recent study showed that co-ingestion of Morus alba extract with $75 \mathrm{~g}$ of sucrose significantly attenuated the increase in blood glucose concentration observed over the initial 120 min of testing in non-diabetic and Type 2 diabetic individuals (Mudra et al., 2007). Morus alba leaves contain active compounds that can inhibit galactosidases, such as 1deoxynojirimycin (Kim et al., 2003), and this effect may help suppress postprandial hyperglycemia by reducing the rate of digestion and absorption of carbohydrates from intestine. However, intraperitoneal administration of Morus alba leaves extract had a hypoglycemic effect in STZinduced hypoinsulinemic diabetic mice (Chen et al., 1995).
Fruit contains chemicals that regulate numerous body functions related to blood pressure, blood viscosity, immune and inflammatory responses (Simopoulos and Salem, 1996). In conclusion, the present study revealed an evident ameliorative effect for Morus alba leaves extract upon the cerebral cortex of maternally diabetic and/ or $\mathrm{Al}$ intoxicated rat pups at both cellular and molecular levels.

\section{References}

Aljanabi, S., Martinez, I. (1997). Universal and rapid salt extraction of high quality genomic DNA for PCRbased techniques. Nucl. Acids Res., 25: 4692-4693.

Andallu, B. Varadacharyulu, N. (2002). Control of hyperglycemia and retardation of cataract by mulberry (Morus indica L.) leaves in streptozotocin diabetic rats. Indian J. Exp. Biol., 40:791-795.

Andriambeloson, E., Baillet, C., Vitte, P., Garotta, G., Dreano, M, Callizot, N. (2006). Interleukin-6 attenuates the development of experimental diabetes-related neuropathy. Neuropathology, 26:32-42.

Auer, R. Wieloch, T. Olsson, Y. Siesjo, B. (1984). The distribution of hypoglycemic brain damage. Acta Neuropathol, 64:177-191.

Auer, R., Hugh, J., Cosgrove, E., Curry, B. (1989). Neuropathologic findings in three cases of profound hypoglycemia. Clin. Neuropathol, 8:63-68.

Aybar, M., Sánchez Riera, A., Grau, A., Sánchez S. (2001). Hypoglycemic effect of the water extract of Smallantus sonchifolius (yacon) leaves in normal and diabetic rats. J. Ethnopharmacol, 74:125-132.

Basnet, P., Kadota, S., Shimizu, M. Xu, H., Namba, T. (1993). 2'-Hydroxymatteucinol, a new C-methyl flavanone derivative from Matteccia orientalis; potent hypoglycemic activity in streptozotocin (STZ)-induced diabetic rat. Chem. Pharm. Bull., 41:1790-1795.

Bishop, N., Morley, R., Chir, B., Day, J., Lukas A. (1997). Aluminum neurotoxicity in preterm infants receiving intravenous feeding solutions. N. Engl. J. Med., 336:1557-1561.

Bose, P. (1989). Genetic resources of mulberry and utilization. Mysore, India: CSR and TI, 183-190.

Brownlee, M. (2005). The pathobiology of diabetic complications: a unifying mechanism. Diabetes, 54:16151625 .

Buchanan, T. Kitzmiller, J. (1994). Metabolic interactions of diabetes and pregnancy. Annu. Rev. Med., 45:245.

Chalmers, J., Risk, M., Kean, D. Grant, R., Ashworth, B. Campbell, I. (1991). Severe amnesia after hypoglycemia. Diabetes Care, 14:922-925.

Chen, F., Nakashima, N., Kimura, I., Kimura, M. (1995). Hypoglycemic activity and mechanisms of extracts from mulberry leaves (Folium Mori) and Cortex Mori Radicis in streptozotocin-induced diabetic mice. Yakugaku Zasshi, 115:476-482.

Cheng, J., Liu, I., Chi, T., Su, H., Chang, C. (2001). Metformin-like effect of Quei Fu Di Huang Wan, a 
Chinese herbal mixture, on streptozotocin-induced diabetic rat. Horm. Metab. Res., 33:727-732.

Comi, G., Corbo, M. (1998). Metabolic neuropathies. Curr. Opin. Neurol., 11:523- 529.

Cranmer, J., Wilkins, J., Cannon, D., Smith, L. (1986). Fetal placental-maternal uptake of aluminum in mice following gestational exposure: effect of dose and route of administration. Neurotoxicology, 7: 601-608.

Dobson, C., Day, J. King, S., Itzhaki R. (1998). Location of aluminum and gallium in human neuroblastoma cells treated with metal-chelating agent complexes. Toxicol. Appl. Pharmacol., 152: 145-152.

Dyck, P., Giannini, C. (1996). Pathologic alterations in the diabetic neuropathies of humans: a review. J. Neuropathol. Exp. Neurol., 55:1181-1193.

Eddouks, M., Maghrani, M., Michel, J. (2005). Hypoglycaemic effect of Triticum repens P. Beauv. in normal and diabetic rats. J. Ethnopharmacol., 102:228-232.

El-Fiky, F., Abou-Karam, M., Afify, E. (1996). Effect of Luffa aegyptiaca (seeds) and Carissa edulis (leaves) extracts on blood glucose level of normal and streptozotocin diabetic rats. J. Ethnopharmacol., 50:43-47.

El-Hilaly, J., Tahraoui, A., Israili, Z., Lyoussi, B. (2006). Hypolipidemic effects of acute and sub-chronic administration of an aqueous extract of Ajuga iva L. whole plant in normal and diabetic rats. J. Ethnopharmacol., 105:441-448.

El-Sayyad, H., El-Sherbiny, M., Sobh, M., Abou-ElNaga, A., Ibrahim, M. Mousa, S. (2011). Protective effects of Morus alba leaves extract on ocular functions of pups from diabetic and hypercholesterolemic mother rats. Int. J. Biol. Sci., 7: 715-728.

El-Sayyad, H., Badawy, G., Hassab Elnabi, S., ElElaimy, I., Al Shehari E. (2015). Ameliorative effect of Morus alba leaves extract against developmental retinopathy in pups of diabetic and aluminum intoxicated pregnant albino rats. Asian Pacific J. Trop. Biomed., 5: 300-309.

Fazan, V., de Vasconcelos, C., Valença, M., Nessler, R., Moore, K. (2010). Diabetic peripheral neuropathies: A morphometric overview. Int. J. Morphol., 28:51-64.

Freinkel, N., Banting Lecture (1980). Of pregnancy and progeny. Diabetes, 29: 1023-1035.

Grover, J. Vats, V. Rathi, S. (2001): Dawar R. Traditional Indian anti-diabetic plants attenuate progression of renal damage in streptozotocin induced diabetic mice. J. Ethnopharmacol., 76:233-238.

Gupta, S. (1995). Statistical methods. New Delhi: Sultan Chand and Sons.

Hao, Z. Hang, B., Wang, Y. (1992). Hypoglycemic effect of Fructus Ligustri Lucidi. Zhongguo Zhong Yao Za Zhi., 17:429-431.

Harati, Y. (2007). Diabetic neuropathies: unanswered questions. Neurol Clin, 25:303-317.

Hassab El-Nabi, S. (2004). Molecular and cytogenetic studies on the antimutagenic potential of eugenol in human lymphocytes culture treated with depakine and apetryl drugs. J. Egypt. Ger. Soc. Zool., 43: 171-196.
Holemans, K., Gerber, R., Meurrens, K., De Clerck, F., Poston, L., Van Assche, F. (1999). Streptozotocin diabetes in the pregnant rat induces cardiovascular dysfunction in adult offspring. Diabetologia, 42: 81-89.

Iizuka, Y. Sakurai, E. Tanaka, Y. (2001). Antidiabetic effect of Folium mori in GK rats. Yakugaku Zasshi, 121:365-369.

Jeronimo, A., Jeronimo, C., Rodrigues Filho, O., Sanada, L., Fazan, V. (2008). A morphometric study on the longitudinal and lateral symmetry of the sural nerve in mature and aging female rats. Brain Res., 1222:51-60.

Johnson, P., Doll, S. Cromey, D. (1986). Pathogenesis of diabetic neuropathy. Ann. Neurol.,19: 450457.

Jouad, H., Maghrani, M., Eddouks, M. (2002). Hypoglycaemic effect of Rubus fructicosis L. and Globularia alypum L. in normal and streptozotocin-induced diabetic rats. J. Ethnopharmacol., 3:351-356.

Kim, H., Jang, M., Shin, M., Chang, H., Lee, T., Lim, B., Jung, C. Lee, C., Kim, C. (2003). Folium mori increases cell proliferation and neuropeptide $\mathrm{Y}$ expression in dentate gyrus of streptozotocin-induced diabetic rats. Biol. Pharm. Bull., 26:434-437.

Krewski, D. Yokel, R., Nieboer, E., Borchelt, D., Cohen, J., Harry, J., Kacew, S., Lindsay, J., Mahfouz, A., Rondeau, V. (2007). Human health risk assessment for aluminum, aluminum oxide, and aluminum hydroxide. J. Toxicol. Environ. Health. B Crit. Rev., 10: 1-269.

Kumar, V., Gill, K. (2014). Oxidative stress and mitochondrial dysfunction in aluminum neurotoxicity and its amelioration: a review. Neurotoxicity, 41:154-166.

Linton, R., Bryan, S., Griffis, D., Shelburne, J., Fiori, C., Garruto, R. (1987). Digital imaging studies of aluminum and calciumin in neurofibrillary tangle-bearing neurons using SIMS (secondary ion mass spectrometry). Trace Elem. Med., 4: 99-104.

Madsen-Bouterse, S., Zhong, Q, Mohammad, G., Ho, Y., Kowluru, R. (2010). Oxidative damage of mitochondrial DNA in diabetes and its protection by manganese superoxide dismutase. Free Radic. Res., 44:313-321.

Matsumoto, H., Hirasawa, E., Torikai, H., Takahashi E. (2004). Localisation of absorbed aluminum in pea root and its binding to nucleic acid. Plant Cell Physiol., 17: 127137.

Mazumder, P. Rathinavelusamy, P., Sasmal D. (2012). Role of antioxidants in phytomedicine with special reference to antidiabetic herbs. Asian Pac. J. Trop. Dis., S969-S979.

Mizisin, A., Shelton, G., Wagner, S., Rusbridge, C., Powell, H. (1997). Myelin splitting, Schwann cell injury and demyelination in feline diabetic neuropathy. Acta Neuropathol, 95: 171-174.

Moreira, P., Santos, M., Seiça, R., Oliveira, C. (2007). Brain mitochondrial dysfunction as a link between Alzheimer's disease and diabetes. J. Neurol. Sci., 257:206214.

Mudra, M., Ercan-Fang, N., Zhong, L., Furne, J., Levitt M. (2007). Influence of mulberry leaf extract on the 
blood glucose and breath hydrogen response to ingestion of $75 \mathrm{~g}$ sucrose by type 2 diabetic and control subjects. Diabetes Care,30:1272-1274.

Muller, G., Hutin, M., Burnel, D., Lehr P. (1992). Aluminum transfer through milk in female rats intoxicated by aluminum chloride. Biol. Trace Elem. Res., 34:79-87.

Mutalib, L. (2015). Comparison between phytotherapy and conventional drug therapy used in urolithiasis management in Hawler city, Kurdistan RegionUraq. J. Pharmacogn. Phytochem., 4: 83-86.

Ornoy, A., Kimyagarov, D., Yaffe, P., Raz, I., Cohen, R.. (1996). Role of reactive oxygen species in diabetesinduced embryo toxicity: studies on pre-implantation mouse embryos cultured in serum from diabetic pregnant woman. Isr. J. Med. Sci., 32:1066-1073.

Ornoy, A. (2007). Embryonic oxidative stress as a mechanism of teratogenesis with special emphasis on diabetic embryopathy. Reprod. Toxicol., 24: 31-41.

Povoski, S., McCullough, P., Zhou, W., Bell, R Jr. (1993). Induction of diabetes mellitus in Syrian golden hamsters using stored equilibrium solutions of streptozotocin. Lab. Anim. Sci., 43: 310-314.

Rao, K., Rao, R., Shanmugavelu, P., Menon, R. (1999). Trace elements in Alzheimer's disease brain: a new hypothesis. Alzheimer's Rep., 2: 241-246.

Ryan, C. (2006). Diabetes and brain damage: more (or less) than meets the eye? Diabetol, 49:2229-2233.

Sasaki, Y., Saga, A., Akasaka, M., Yoshida, K., Nishidate, E., Su, Y. et al. (1997). In vivo genotoxicity of ortho-phenylphenol, biphenyl, and thiabendazole detected in multiple mouse organs by the alkaline single cell gel electrophoresis assay. Mutat. Res., 395: 189-198.

Sato, K., Carmo, J., Fazan, V. (2004). Morfologia do nervo renal no diabete experimental crônico em ratos. Arquivos de Ciências da Saúde da UNIPAR, 8:69-71.

Shams-Ardekani, M., Barin, A., Vakili-Saatloo, N., Sadighara, P. (2013). The cytoprotective effects of Morus alba leaves in cultured fetus fibroblast cells against hyperglycemia. Zahedan J. Res. Med. Sci., 15: 52-54.

Sharma, A., Bajada, S., Thomas, P. (1981). Influence of streptozotocin-induced diabetes on myelinated nerve fibre maturation and on body growth in the rat. Acta Neuropathol., 53:257-265.

Sharma, A Thomas, P. (1987). Animal models: Pathology and pathophysiology. In Diabetic Neuropathy (ed. Dyck PJ, Thomas PK, Asbury AK, Winegrad AI, Porte D Jr), 237-252. Philadelphia: W. B. Saunders.

Sharma, P. Mishra, K. (2006). Aluminum-induced maternal and developmental toxicity and oxidative stress in rat brain: Response to combined administration of Tiron and glutathione. Reprod. Toxicol., 21: 313-321.

Simopoulos, A., Salem, N. (1996). Fatty acids and lipids from cell biology to human disease. Lipids, 31: S1.

Singab, A., El-Beshbishy, H., Yonekawa, M., Nomura, T., Fukai, T. (2005). Hypoglycemic effect of Egyptian Morus alba root bark extract: Effect on diabetes and lipid peroxidation of streptozotocin-induced diabetic rats. J. Ethnopharmacol., 100:333-338.
Thomas, P., Eliasson, S. (1984). Diabetic neuropathy. In : Dyck PJ, Thomas PK, Lambert EH, Bunge R, eds. Peripheral Neuropathy. 2nd Edition, Philadelphia, WB Saunders, 1773-1810.

Thomas, P., Fraher, J., O'Leary, D., Moran, M., Cole, M., King, R. (1990). Relative growth and maturation of axon size and myelin thickness in the tibial nerve of the rat. 2. Effect of streptozotocin-induced diabetes. Acta Neuropathol., 79:375-386.

Tomlinson, D., Gardiner, N. (2008). Glucose neurotoxicity. Nat Rev Neurosci, 9:36-45.

Van Dijk, G., Van Heijningen, S. Reijne, A. Nyakas, C. Van der Zee, E. Eisel, U. (2015). Integrative neurobiology of metabolic diseases, neuroinflammation, and neurodegeneration. Front Neurosci., 9:173-179.

Van Ginkel, M., Van der Voet, G., De Wolff, F. (1990). Improved method of analysis for aluminum in brain tissue. Clin. Chem., 36: 658-61.

Vinik, A., Park, T., Stansberry, K., Pittenger, G. (2000). Diabetic neuropathies. Diabetology, 43:957-973.

Wallace, D. (1999). Mitochondrial diseases in man and mouse. Science, 283:1482-1488.

Weberg, R., Berstad, A., Ladehaug, B., Thomassen, Y. (1986). Are aluminum containing antacids during pregnancy safe? Acta Pharmacol. Toxicol., 59:S63-S65.

Xiu, L., Miura, A., Yamamoto, K., Kobayashi, T., Song, Q., Kitamura, H., Cyong, J. (2001). Pancreatic islet regeneration by ephedrine in mice with streptozotocininduced diabetes. Am. J. Chin. Med., 29:493-500.

Yagihashi, S., Nishihira, M., Baba, M. (1979). Morphometrical analysis of the peripheral nerve lesions in experimental diabetes rats. Tohoku J. Exp. Med., 129: 139149.

Yokel, R. (1985). Toxicity of aluminum exposure during lactation to the maternal and suckling rabbit. Toxicol. Appl. Pharmacol., 75:35- 43.

Yokel, R. (2000). The toxicology of aluminum in the brain: a review. Neurotoxicol, 21: 813-828.

Yumoto, S., Nagai, H., Matsuzaki, H., Matsumura, H., Tada, W., Nagatsuma E., Kobayashi K. (2001). Aluminum incorporation into the brain of rat fetuses and sucklings. Brain Res. Bull., 55:229-234. 